\title{
SÍNTESE E CARACTERIZAÇÃO DA ZEÓLITA Y A PARTIR DE METACAULIM
}

\author{
L. B. BORTOLATTO ${ }^{1}$, J. C. MOREIRA ${ }^{1}$, D.R. CONSONI ${ }^{1}$, H. G. RIELLA ${ }^{1}$, N. C. \\ KUHNEN $^{1}$, M.P.M.MARTINS ${ }^{2}$. \\ ${ }^{1}$ Universidade Federal de Santa Catarina, Departamento de Engenharia Química e \\ Engenharia de Alimentos \\ ${ }^{2}$ Universidade do Sul de Santa Catarina, Unisul \\ E-mail para contato: larissa.bbort@ hotmail ${ }^{1}$, jarina_moreira@ hotmail.com $^{1}$, \\ deise.r.c@ufsc.br ${ }^{1}$,riella@enq.ufsc.br ${ }^{1}$,nivaldo@enq.ufsc.br ${ }^{1}$, maria.ana@unisul.br ${ }^{2}$
}

RESUMO - Zeólitas Y são aluminossilicatos com ampla aplicação industrial devido às suas propriedades. O material zeolítico foi sintetizado utilizando como fonte principal de silício e alumínio um rejeito de caulim previamente calcinado (metacaulim). O processo de síntese ocorreu em condições hidrotermais e os efeitos das relações $\mathrm{Si} / \mathrm{Al}$ e $\mathrm{Na} / \mathrm{Al}$ também foram considerados. $\mathrm{O}$ material de partida e as fases formadas como produtos de reação foram caracterizados por difração de raios X, microscopia eletrônica de varredura e espectroscopia de absorção na região do infravermelho. As análises evidenciaram que o material possui picos característicos da estrutura de zeólita $\mathrm{Y}$ e as imagens de MEV, mostraram que o material possui uma morfologia homogênea, com tamanho uniforme. Os resultados indicam que a metodologia utilizando metacaulim e uma fonte adicional de sílica foi efetiva na produção de uma zeólita Y com boa cristalinidade na fase predominante.

\section{INTRODUÇÃO}

Atualmente estão sendo realizadas muitas pesquisas, com o intuito de desenvolver novos materiais para adsorção de poluentes químicos, proveniente das indústrias em geral. As zeólitas, por suas propriedades físico-químicas e morfológicas são materiais promissores podendo ser utilizadas para o desenvolvimento de tecnologias de alta eficiência que possam contribuir com a manutenção e a sustentabilidade do meio ambiente.

Zeólitas são aluminossilicatos com uma estrutura de rede definida, incluindo cavidades ocupadas por íons e moléculas de água, ambos os quais possuem uma considerável liberdade de movimento, o que torna possível fenômenos como troca iônica e desidratação. Por possuir propriedades tais como: estrutura cristalina bem definida, grande área específica, alto grau de acidez, facilidade de introdução de diferentes cátions por troca iônica, entre outras, apresentam grande importância industrial. Atualmente são conhecidas mais de 190 diferentes tipos de estruturas zeolíticas, podendo-se destacar a zeólita Y (FAU) como uma de grande importância industrial (Gianetto, 2000).

As zeólitas Y são formadas por cristais de alumino silicato, com aspecto de um pó muito fino, caracterizadas pela presença de pequenos microporos dentro de seus cristais, sendo usadas como adsorventes seletivos nos processos de separação e purificação de hidrocarbonetos, e, em sua forma ácida, é o principal componente de catalisadores utilizados em craqueamento de petróleo (Trif, 1994). 
A procura de matérias-primas mais econômicas resultou nos processos provenientes da utilização de argilominerais, dos quais o caulim é o mais empregado, pois constituem uma fonte natural de $\mathrm{Al}_{2} \mathrm{O}_{3}$ e $\mathrm{SiO}_{2}$ em substituição aos reagentes químicos tradicionais utilizados como o aluminato de sódio e sílica (Breck, 1984).

Para Santos 1989, caulim é o nome comercial dado a um tipo de argila de coloração branca, composta principalmente do mineral caulinita. Os caulins são aluminossilicatos hidratados, cuja composição química aproxima-se de $\mathrm{Al}_{2} \mathrm{Si}_{2} \mathrm{O}_{5}(\mathrm{OH})_{4}$, o que corresponde a cerca de $46,54 \%$ de $\mathrm{SiO}_{2}, 39,50 \%$ de $\mathrm{Al}_{2} \mathrm{O}_{3}$ e $13,96 \%$ de $\mathrm{H}_{2} \mathrm{O}$ (Coelho, et al 2007).

O Brasil é hoje um dos maiores produtores mundiais de caulim processado. A diversidade de geologia está refletida nos diversos ambientes em que as associações de argilominerais cauliníticos se formaram em muitos lugares do país (Melo, 2010). O caulim possui vários usos em papel, cerâmicas, borracha, plásticos, dentre outros. Produtos de valor agregado do caulim incluem caulim para pigmento, cerâmicas de alta qualidade, zeólitas de baixa sílica e catalisadores de craqueamento. Por meio de um tratamento térmico do caulim, a elevadas temperaturas e tempos pré-determinados, obtém-se o metacaulim (Gardolinski et. al., 2003). Este é mais reativo que o caulim e os minerais assistentes podem ser convertidos a óxidos.

O produto zeolítico mais comum preparado a partir de caulim ou metacaulim é a zeólita A (relação Si/Al igual a 1); outros tipos de zeólitas com maior relação Si/Al, como a zeólita X e Y, também podem ser obtidas, para isto, deve-se adicionar ao material de partida, uma fonte adicional de sílica, ou então, através de métodos de lixiviação, procura-se retirar certa quantidade do alumínio que compõe a estrutura da caulinita (Hildebrando, 2012).

As zeólitas X e Y, apesar do nome diferente, apresentam a mesma estrutura cristalina, ambas são do tipo faujasita (FAU), suas diferenças residem na relação Si/Al intrareticular; quando esta relação se encontra na faixa de 1 a 1,5 é designada como zeólita $\mathrm{X}$, e da mesma forma para valores mais altos como zeólita Y (Gianetto, 2000).

O principal objetivo deste estudo foi o desenvolvimento de uma rota técnica e economicamente viável para a síntese de zeólitas Y, a partir de argila do tipo caulim como fonte de silício e alumínio. As matérias-primas e a zeólita Y sintetizada foram caracterizadas por difração de raios X (DRX), microscopia eletrônica de varredura (MEV) e espectroscopia na região do infravermelho por transformada de Fourier (FTIR).

\section{MATERIAIS E MÉTODOS}

\subsection{Materiais de Partida}

O caulim utilizado como fonte de silício e alumínio, foi originado no processo de beneficiamento produzido pela empresa Caulisa, localizada na região de Campina Grande, no estado do PB. Esse caulim foi submetido a um processo de calcinação, realizado em forno mufla na temperatura de $850^{\circ} \mathrm{C}$ por 2 horas para a conversão em metacaulim, uma fase amorfa e consideravelmente mais reativa. O metacaulim foi peneirado em peneira de 200 mesh para ajuste do tamanho de partículas. 


\subsection{Síntese de zeólita Y a partir de metacaulim}

O procedimento detalhado de síntese foi realizado em quatro etapas, como segue abaixo (adaptado da metodologia IZA - International Zeolite Association):

Etapa 1: 10,0 g de metacaulim e 15,0 g de hidróxido de sódio foram dispersos em $100 \mathrm{~g}$ de água deionizada sob agitação, durante 30 minutos. Razão metacaulim/ $\mathrm{NaOH}=1 / 1,5 \mathrm{em}$ massa (HTAY E OO, 2008).

Etapa 2: como o metacaulim apresenta relação $\mathrm{Si} / \mathrm{Al}=1$ e a zeólita $\mathrm{Y}$ apresenta relação $\mathrm{Si} / \mathrm{Al}>$ 1,5 (HILDEBRANDO, 2012), foi necessário adicionar uma fonte de silício para ajustar as quantidades. Assim, para $\mathrm{Si} / \mathrm{Al} \cong 2,5,13,8 \mathrm{~g}$ de silicato de sódio $\left(\mathrm{Na}_{2} \mathrm{SiO}_{3}\right)$ foram dispersos em $50 \mathrm{~g}$ de água deionizada sob agitação, durante 30 minutos, até a formação de um gel. Esse gel permaneceu em repouso por 24 horas.

Etapa 3: Após esse período as soluções da etapa 1 e etapa 2 foram transferidos para uma autoclave de aço inoxidável e teflon e levado a estufa, onde permaneceu por 6 horas a uma temperatura de $100^{\circ} \mathrm{C}$.

Etapa 4: Finalmente, o produto sólido foi lavado até $\mathrm{pH}$ aproximadamente 9,0 e centrifugado com água, em seguida a amostra foi seca em estufa a $60^{\circ} \mathrm{C}$ por aproximadamente 24 horas. Após esse processo a amostra foi triturada em um almofariz.

O material de partida e as fases formadas no produto de síntese foram caracterizados por meio de: difração de raios $\mathrm{X}$ (DRX) em difratômetro X'Pert (Philips) com anodos de $\mathrm{Cu}$, varredura de $10^{\circ}$ a $90^{\circ}$ em $2 \Theta, 40 \mathrm{kV}$ e $30 \mathrm{~mA}$; microscopia eletrônica de varredura (MEV) com imagens obtidas em aparelho da marca Phillips XL30 - da marca JEOL JSM-6390LV Scanning Electron Microscope, com o objetivo de obter a caracterização morfológica e química dos materiais; e espectroscopia de infravermelho (FTIR) em equipamento da marca Shimadzu, modelo IR Prestige-21 com transformada de Fourier. Os espectros de infravermelho foram registados a partir de $4000 \mathrm{~cm}^{-1}-400 \mathrm{~cm}^{-1}$ e resolução $4 \mathrm{~cm}^{-1}$.

A metodologia adotada na realização dos ensaios de síntese, para obtenção do produto zeolítico, encontra-se representada de forma esquemática em seus principais estágios na Figura 1.

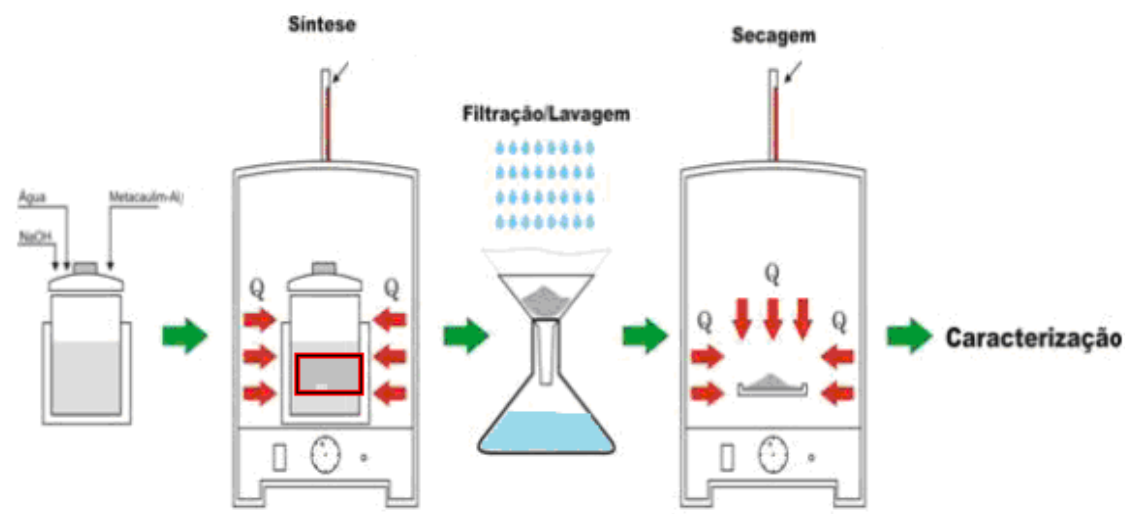

Figura 1: Fluxograma do processo de produção de zeólitas Y. 


\section{RESULTADOS E DISCUSSÕES}

\subsection{Difratograma de raios X (DRX)}

A técnica de difração de raios $\mathrm{X}$ foi utilizada com o objetivo de observar a cristalinidade do material sintetizado no laboratório, bem como proceder a sua identificação.

A análise mineralógica do caulim por difração de raios X na Figura 2a indica que este é constituído principalmente do argilomineral caulinita, encontrando-se também outros minerais secundários em menor proporção como quartzo. Pela observação do aspecto da curva de difração da Figura 2b, nota-se uma perda de cristalinidade, indicando assim, que o processo de metacaulinização a $850^{\circ} \mathrm{C}$ por $2 \mathrm{~h}$ foi eficiente, tornando-se então o material uma fonte propícia para a síntese de zeólitas pois acima da temperatura de desidroxilação a conversão de caulinita em metacaulinita torna a argila mais reativa, variando esta reatividade com o tratamento térmico, o que de certo modo pode afetar no mecanismo e na cinética da reação de zeolitização.

A Figura 2c mostra o difratograma de raios $\mathrm{X}$ da zeólita $\mathrm{Y}$ sintetizada, onde estão identificados picos bem definidos, indicando que a zeólita $\mathrm{Y}$ foi obtida no tempo 6 horas e $100{ }^{\circ} \mathrm{C}$. Essa amostra apresenta picos correspondentes aos característicos da zeólita $\mathrm{Y}$, com os valores de 2 theta $\mathrm{em}: 6,17^{\circ} ; 10,25^{\circ} ; 11,80^{\circ} ; 15,54^{\circ} ; 18,60^{\circ} ; 20,30^{\circ} ; 23,56^{\circ} ; 26,87^{\circ}$ e $31,16^{\circ}$ que foram relatado por Treacy e Higgins 2001.

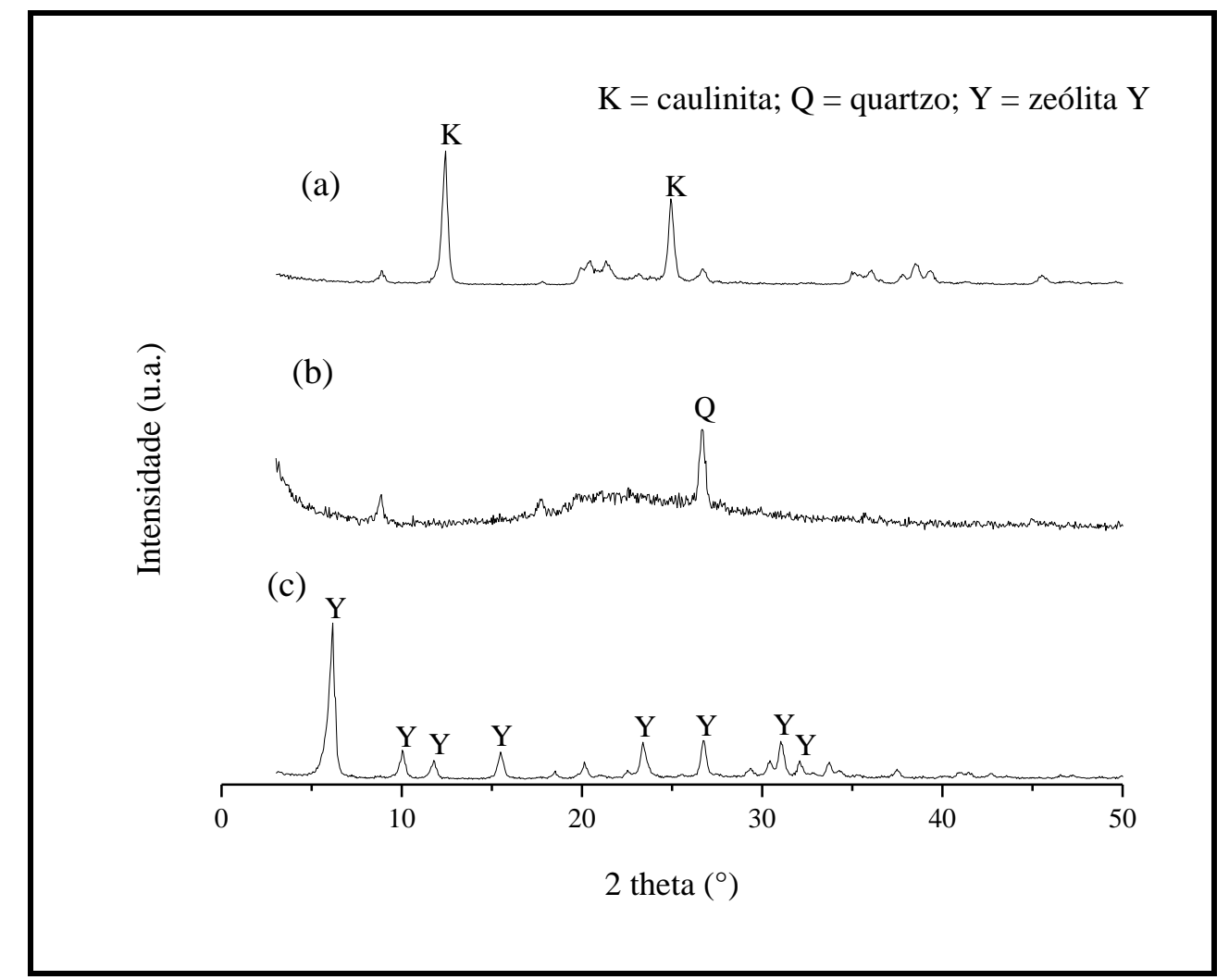

Figura 2: Espectros de DRX: (a) caulim; (b) metacaulim; (c) zeólita Y sintetizada. 


\subsection{Análise de Microscopia Eletrônica de Varredura (MEV)}

É possível observar a morfologia da matéria-prima e do produto obtido através das imagens de MEV na Figura 3. Na Figura 3a tem-se a visão geral das estruturas das partículas do caulim, onde são observados cristais de formato lamelar com bordas irregulares assemelhando-se a hexágonos, isto é, placas pseudo-hexagonais típicas da caulinita, conforme descrito na literatura (Santos, 1989); enquanto que no metacaulim (Figura 3b), o empilhamento é alterado através da diminuição de folhas empacotadas, mantendo-se, porém a forma.

Na Figura 3c, é possível observar-se que a amostra possui uma morfologia homogênea, onde as partículas estão aglomeradas, apresentando tamanho uniforme. Quando Htay e Mya (2008) sintetizaram a zeólita Y obtiveram imagens de MEV com as mesmas características. No qual a zeólita do tipo faujasita é identificada por formas octaédricas (bipiramidal); nota-se na micrografia que o cristal apresenta-se bem definido, indicando assim boa cristalinidade para a fase sintetizada. Cristais com outras formas (cúbicos, esféricos, etc.) não foram encontrados, demonstrando assim, a predominância da fase zeolítica do tipo Y (Hildebrando, 2012).
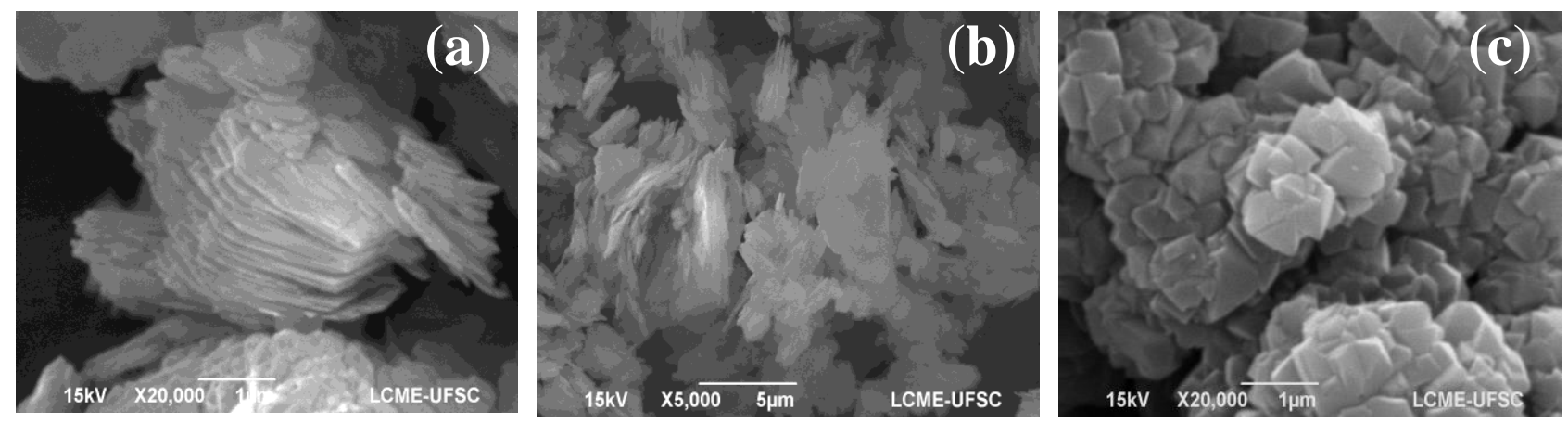

Figura 3: Imagens de MEV: (a) caulim; (b) metacaulim; (c) zeólita Y sintetizada. 


\subsection{Espectroscopia de Infravermelho por Transformada de Fourier (FTIR)}

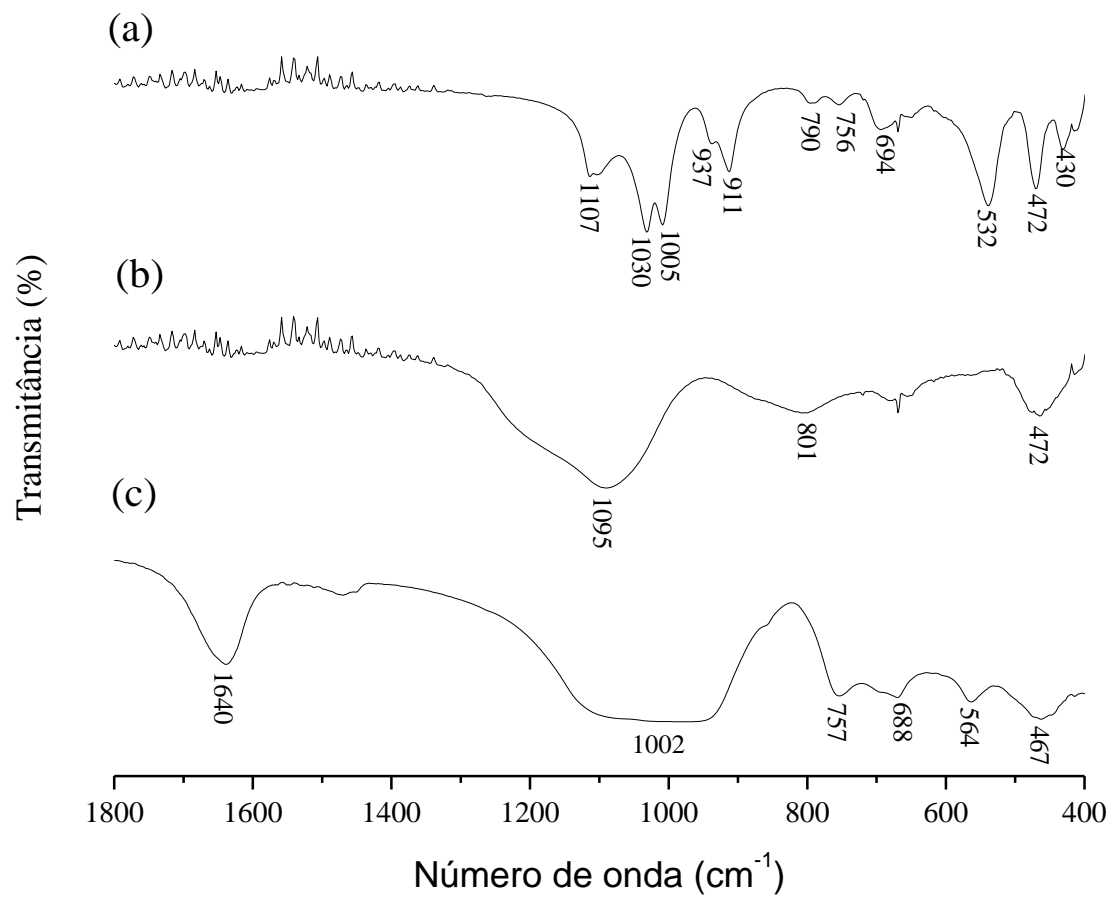

Figura 4: Espectros de absorção na região do Infravermelho FTIR: (a) caulim; (b) metacaulim; (c) zeólita Y sintetizada.

A transformação de caulim em metacaulim e, em seguida, para uma zeólita pode ser observado a partir do espectro de FTIR (Figura 4), na região da estrutura $\left(1400-400 \mathrm{~cm}^{-1}\right.$ ). O material de partida, o caulim (Figura 4a), apresenta bandas bem definidas nesta região devido a Si$\mathrm{O}$, Si-O-Al, e vibrações Al-OH. A conversão para metacaulim (Figura 4b), remove totalmente essas bandas, deixando uma larga faixa assimétrica intensa em $1095 \mathrm{~cm}^{-1}$ como a principal característica. O desaparecimento das bandas 911 e $937 \mathrm{~cm}^{-1}$ indica a perda de unidades de Al$\mathrm{OH}$, enquanto o o desaparecimento da Si-O-Al bandas a 790 e $756 \mathrm{~cm}^{-1}$ são consistentes com distorção das camadas de tetraedros e octaédricos (Loiola, 2012).

No espectro de FTIR da Figura 3c, as freqüências observadas em torno de 1640, 1002, 757, 688,564 e $467 \mathrm{~cm}^{-1}$ sugerem que na amostra produzida existe material zeolítico com estrutura do tipo FAU, pois estas encontram características semelhantes àquelas relatadas para zeólita Y conforme a literatura (Qiang, 2010). 


\section{CONCLUSÃO}

Zeólita Y foi obtida através de uma nova rota, baseada e adaptada na síntese padrão IZA, empregando argila tipo caulim como fonte de silício e alumínio.

As análises de difração de raios $\mathrm{X}$ e microscopia eletrônica de varredura confirmaram a formação da zeólita $\mathrm{Y}$ evidenciando que o material analisado possui um alto grau de cristalinidade. Estes dados demonstraram que o método de síntese utilizado neste estudo são adequados para a síntese desta zeólita Y na forma pura.

A imagem de MEV em alta resolução (20.000), mostrou claramente a morfologia do material e a formação de cristais, o que concorda com a literatura atual. Finalmente, a transformação de metacaulim para o zeólita Y pode ser monitorada e avaliada por meio de FTIR.

Todos estes resultados mostram que o método de síntese de zeólitas, com base na utilização de caulim como matéria-prima é altamente eficiente. Dessa forma, o caulim pode ser reaproveitado saindo da condição de poluente para se tornar uma opção para soluções de problemas ambientais.

\section{AGRADECIMENTOS}

Coordenação de Aperfeiçoamento de Pessoal de Nível Superior (CAPES / DS).

\section{REFERENCIAS}

G. GIANETTO, A. MONTES, G. RODRÍGUEZ, Zeolitas: Características, propriedades y aplicaciones industriales, $2^{\mathrm{a}}$ Ed., Editorial Innovación Tecnológica, Caracas, Venezuela, 2000 .

TRIF, E.; STRUGARU, D.; IVAN, I.; RUSSU, R.; GHEORGHE, G. \& NICULA, A. (1994), “Thermal properties of Y-type zeolites", Journal of Thermal Analysis, vol. 41, p. 871-880.

BRECK, D. W. Zeolite molecular sieves. New York: John Wiley \& Sons, Inc., 1984.

SANTOS, P. S. Ciência e tecnologia das argilas. $2^{\mathrm{a}}$ ed. São Paulo: Edgard Blücher Ltda. 1989, v. 1.

COELHO, A.C.V.; SANTOS, P.S.; SANTOS, H.S. Argilas especiais: argilas quimicamente modificadas - uma revisão. Química Nova, v.30, p. 1282-1294, 2007.

GARDOLINSKI, J.E.; FILHO, H.P.M.; WYPYCH, F. Comportamento térmico da caulinita hidratada. Química Nova, v.26, p. 30-35, 2003.

HILDEBRANDO, E. A.; ANGELICA, R. S.; NEVES, F.R.; VALENZUELA-DIAZ, F. R.; Síntese de zeólita do tipo faujasita a partir de um rejeito de caulim. Cerâmica, v.58, p. 453458, 2012. 
HTAY, M. M.; OO, M. M.; Preparation of Zeolite Y Catalyst for Petroleum Cracking. World Academy of Science, Engineering and Technology. Vol:24. p 108-114, 2008.

MELO, C. R.; RIELLA, H. G.; Síntese de zeólita tipo NaA a partir de caulim para obtenção de zeólita 5A através de troca iônica. Cerâmica v. 56, p. 340-346, 2010.

TREACY, M.J.; HIGGINS, J.B. Collection of simulated XRD powder patterns for zeolites. $4^{\mathrm{a}}$ ed., p. 379. Elsevier, Amsterdam, The Netherlands, 2001.

QIANG, L.; YING, Z.; ZHIJUN, C.; WEI, G.; LISHAN, C. Influence of synthesis parameters oh the crystallinity and $\mathrm{Si} / \mathrm{Al}$ ratio of $\mathrm{NaY}$ zeolite synthesized from kaolin. Petroleum Science, v.7, p. 403-409, 2010.

LOIOLA, A.R.; ANDRADE, J.C.R.A.; SASAKI, J.M. Sasaki.; SILVA, L.R.D. Structural analysis of zeolite NaA synthesized by a cost-effective hydrothermal method using kaolin and its use as water softener. Journal of Colloid and Interface Science, v. 367, p.34-39, 2012.

Structure Commission of the International Zeolite Association (SC-IZA), disponível em: http://www.iza-structure.org/databases acessada em abril 2014. 